\title{
Sustainable Guideline for Developing the E-Waste Sector in Egypt
}

\author{
Ahmed Tarek, Salah El-Haggar \\ School of Sciences and Engineering, The American University in Cairo, Cairo, Egypt \\ Email: ahmedtark@aucegypt.edu
}

How to cite this paper: Tarek, A. and El-Haggar, S. (2019) Sustainable Guideline for Developing the E-Waste Sector in Egypt. Journal of Environmental Protection, 10, 1043-1071. https://doi.org/10.4236/jep.2019.108062

Received: July 12, 2019

Accepted: August 19, 2019

Published: August 22, 2019

Copyright $\odot 2019$ by author(s) and Scientific Research Publishing Inc. This work is licensed under the Creative Commons Attribution-NonCommercial International License (CC BY-NC 4.0). http://creativecommons.org/licenses/by-nc/4.0/ (c) (i) (8) Open Access

\begin{abstract}
The amount of electronic waste generated globally is alarming especially that it is on the rise. The impact of the generated amounts is not only Environmental. The electronic waste sector is unregulated in most developing countries; this results in the informal sector being heavily involved in managing and handling it. Due to the lack of regulations, informal handlers are exposed to hazardous materials that affect both their health and health of the communities living in their proximity. Moreover, the informal sector involves illegal child and women labor under harsh conditions. In addition to the social impact, the lack of regulations leads to missing major economic opportunities associated with developing a recycling industry for the safe handling and material recovery from the generated e-waste volumes. Electronic waste may contain up to 60 different materials including precious and rare-earth metals with estimated equivalent economic value of 48 billion Euros. Egypt is one the countries which lack policies and regulations dedicated to e-waste, hence the Egyptian economy is missing the economic potential and job creation opportunities associated with developing the e-waste sector as well as facing major Environmental and health challenges due to the improper handling of the generated amounts. This paper briefly reviews the current situation of e-waste in Egypt. The paper then proposes an adapted guideline for the sustainable management of e-waste in Egypt. The guideline is based on the international regulations and guidelines especially those of countries similar to the Egyptian socioeconomic context. The produced guideline focuses on establishing a collection and recycling framework for e-waste in Egypt with EPR at its center. The guideline also establishes a financing system to help foster the recycling industry in Egypt while fulfilling the three main pillars of sustainability.
\end{abstract}

\section{Keywords}

E-Waste, E-Waste Management, Sustainable Guidelines, E-Waste in Egypt 


\section{Introduction}

Electronics and electronic devices have become a significant part of everyday life for the billions of people living around the globe. The technological advancement in material science coupled with the demand for better lifestyles is the reason behind such a massive penetration. However, this advancement comes at a cost which was not recognized until recently. The amount of waste generated from the disposal of electronics and electronic devices, known as E-waste, has been rising ever since. E-waste is the waste generated from any device or equipment that uses electricity to operate and has reached its end of life cycle or is disposed of due to technological advancements. These devices include, but are not exclusive to, computers, cellphones, large equipment such as washing machines and refrigerators, and small equipment such as vacuum cleaners and toasters [1] [2] [3].

The reason behind the significance of e-waste lies in its economic potential and environmental threats. E-waste consists of a combination of materials some of which are toxic and hazardous, and others are not easily degradable. Among the different materials that can be found in e-waste are metals, plastics, glass and rare earth elements [1]. When e-waste is not included in a recycling scheme and is disposed of in dumpsites, landfills, and incinerators, these materials are lost, and with it, a tremendous economic opportunity is wasted in addition to the environmental pollution that is caused. Many of the metals included in e-waste are precious metals like gold, silver, aluminum, and titanium; these metals when recycled help save substantial amounts of money, energy, and pollution that would otherwise result from their extraction and production from their raw ores. Also, improper disposal can affect the environment in which they are dumped or landfilled especially when these heavy metals find their way into the soil and underground water. In addition to the economic and environmental aspects of e-waste, there is a social aspect that is mainly related to health threats due to the informal handling of e-waste by unregulated sectors in developing countries. The exposure to the heavy metals and hazardous byproducts that are released during the handling process has an adverse effect on the communities which are directly exposed to them. Especially children are the most vulnerable to high levels of exposure either as secondhand exposure from their parents who work in the unregulated handling sector or as workers, who are subjected to child labor [3].

Exact quantities of e-waste are hard to estimate. This is due to the fact that most e-waste is handled by the informal sectors or is illegally exported to developing countries where labor cost is cheaper [1] [3]. The exportation purpose of e-waste differs from one country to another; in most Asian countries, the imported e-waste is dismantled by the informal sector whereas, in African countries, they reuse the imported electronic products [4]. Attempts to estimate the volume of e-waste generation show an apparent disparity between the e-waste generation in developed and developing countries with developed countries 
ranking higher [1] [2]. One reason behind such disparity is the high living standards and more luxurious lifestyles. The United States is the largest producer of e-waste globally, and most of the generated waste in 2009 ended up in landfills and incinerators [5]. It was estimated that 41.8 million tons of e-waste was produced in 2014 with large equipment like microwaves, toasters, calculators and ventilation equipment having the highest share [2] [6]. However, only 6.5 million tons of which were documented and appropriately recycled according to the international standards and regulations [6]. The generation of e-waste is expected to continue growing exponentially at rapid rates [2] [3] which should be alarming especially that the e-waste management sector is still underdeveloped. Most studies [1] [2] [3] [4] [5] view the rapid technological advancement which leads to shorter replacement period of electronics as the main reason behind the exponential growth; for instance, the life span of computers has dropped from 4 years to 2 years.

Currently, Egypt has no e-waste regulation that dictates proper and safe handling and treatment of the generated e-waste. The amount of e-waste generated in Egypt in the year 2014 was 0.37 million tons making Egypt amongst the top e-waste generating countries in Africa followed by South Africa and Nigeria [6]. These numbers provide an insight into the size of the e-waste problem Egypt is currently facing which is expected to grow even bigger.

The aim of this paper is to propose an adapted guideline for the sustainable management of e-waste in Egypt. In order to more accurately describe, analyze and propose a solution to the e-waste problem in Egypt, it is essential to firstly define e-waste, study the current situation in Egypt as well as distinctly understand the implications of the problem and the potential opportunities that can be derived from tackling the problem.

\subsection{What Is E-Waste}

The term "e-waste" is a broad umbrella under which many categories fall. However, the definition differs globally, which results in Ununified definition of the problem. Globally, e-waste is agreed to be consumer electronics such as computers, mobile phones, and screens, known as brown goods. On the other hand, inconsistencies in the definition include larger equipment such as refrigerators and air conditioners, known as white goods, microwave ovens and coffeemakers, medical equipment, toys, recreational machines and batteries [1] [7]. It is important to mention that some of these items that are not fully agreed upon as e-waste have their regulations outside the framework of e-waste regulations in some countries. However, this paper will discuss only the consumer electronic waste excluding refrigerators, air conditioners, power machines, etc.

\subsection{Impact of Untreated E-Waste}

There are direct health and safety ramifications resulting from the unregulated informal sectors handling e-waste. Such hazards are partially tied to the negative 
environmental impact of e-waste. E-waste comprises of a variety of materials; among which some are toxic and hazardous heavy metals. When dumped and disposed of in landfills, the leachate produced usually finds its way to the soil and underground water which exposes human health to danger.

On the other hand, incinerators release the toxic gases produced from the combustion of e-waste into the air which also affects the human health in surrounding communities. Most developing countries which import e-waste and recycle it lack regulatory policies that ensure the safety of the workers. In fact, the recycling process is highly primitive and labor dependent; e-waste is dismantled using chisels and hammers, and precious metals like gold are extracted in open-pit acid baths without any proper protection [3]. In addition, in areas where e-waste is treated manually in backyards, the nearby freshwater, soil, and air were found to be contaminated with particles of heavy metals, organic pollutants, and plastics. This was found in recent studies that included global hubs for e-waste manual recycling such as Guiyu and Taizhou in China, Gauteng in South Africa, New Delhi in India, Accra in Ghana and Karachi in Pakistan [4]. Nearby residents to areas of informal e-waste handling are usually exposed to such hazards either directly as laborers or as a secondhand exposure from dealing with workers or from the toxicants entering their food chain through water, air, and soil [4]. High levels of pollutants like heavy metals and toxicants were found in tissue samples from residents living in proximity of e-waste handling areas [1] [4]. Reference [4] compiled the common toxicants produced from e-waste and their impact on human health; many of the substances are carcinogenic whether from direct contact such antimony, beryllium, and nickel or indirectly such as Chlorofluorocarbons which contribute to the erosion of the ozone layer leading to higher occurrences of skin cancer. Many countries including the EU have restrictions on the use of some of these substances in EEE. These restrictions aim to put the usage of such toxicants to a minimum and ensure their proper handling to avoid their harmful impact on the environment and human health.

\subsection{Potential Opportunities}

Before becoming e-waste, products were initially high technology sophisticated commodities. To be manufactured, these products require a variety of materials especially rare earth elements and precious metals, due to their unique characteristics which allow for the high technological advancement. E-waste is an excellent resource for materials; for instance, it is estimated that $43 \%$ of all the gold produced worldwide and 7275 tons of silver end up in the production of electronics [8]. Reference [1] reviewed different papers which calculated the number of materials some of the most common e-waste products enclose; for instance, mobile phone needs around 60 different materials to be manufactured while computers require over 30 materials. Of these materials, metals constitute $50 \%$ of a mobile phone's weight and $60 \%$ of a computer. Among the materials in- 
cluded in e-wastes are metals such as iron, copper, and aluminum in addition to plastics and glass [2]. Estimates of the materials quantities found in e-waste as well as their equivalent economic value that can be gained in case of recycling these materials can be found in Table 1 [6]. Although according to the table, iron steel is the most abundant material found in e-waste in terms of quantity, it does not rank at the top in term of estimated economic value. Surprisingly, plastics account for the highest estimated economic value and also the quantity produced from e-waste is significant. This is important when considering which materials are deemed economically viable to build an industry around their mining from e-waste, treatment and then reuse or recycling in the production of new products. According to one study [8], Printed Circuit Boards (PCBs) are the most valuable part of waste electronics. They contain a mixture of metals, mainly copper at around $30 \%$ and $10 \%-20 \%$ solder in addition to other metals like lead, iron, nickel, gold, and silver with contents ranging between $5 \%$ to $0.01 \%$, as well as non-metals. The purity of these precious metals is relatively high which makes the extraction and recycling of these materials in an environmentally friendly manner attractive [8].

In an investigation, it was found that similar composition patterns are maintained across the EU and Switzerland. The pattern shows that between $47 \%$ and $60 \%$ of the total generated WEEE by weight is iron and steel ranking as the most significant component by weight. Plastics and screens follow with percentages of around $15 \%$ and $12 \%$ respectively [9].

This complexity in materials poses a challenge to the efficient extraction and recycling of these materials from e-waste in order to be further reused instead of being wasted. Most extraction and recycling methods, especially for metals and rare earth elements, are energy-intensive with complex processes and high labor demand [1].

The previous numbers reflect the tremendous economic potential for the recycling of e-waste. The value of materials included in the e-waste generated in 2014 was estimated at 48 billion Euros [6]. Given the large amount of rare and precious materials that are found in electronics, and the increasing demand, environmental resources were put under stress, and some of the major producing

Table 1. Materials found in e-waste and their estimate economic value [6].

\begin{tabular}{ccc}
\hline Material & Quantity (Kilotons) & Estimated Value (Million Euros) \\
\hline Iron, Steel & 16,500 & 9000 \\
Copper & 1900 & 10,600 \\
Aluminum & 220 & 3200 \\
Gold & 0.3 & 10,400 \\
Silver & 1.0 & 580 \\
Palladium & 0.1 & 1800 \\
Plastics (PP, ABS, PC, PS) & 8600 & 12,300 \\
\hline
\end{tabular}


countries introduced restricting policies regarding their production and exportation, this has resulted in price spikes. For instance, after the introduction of the Chinese restriction on the production of neodymium, a rare earth precious metal that is used in the production of magnets and lasers, its price reached $\$ 460,000$ per kg instead of the initial $\$ 40$ [1]. The printed circuit board is considered the most valuable component of e-waste since it has around $40 \%$ of all the metals found in e-waste mainly gold, silver, and palladium. Copper is also another metal that can be found heavily in most e-waste components, for instance, it makes up around $13 \%$ of the weight of a mobile phone, and the percentage reaches $20 \%$ in the case of PC boards [2].

The recycling of materials extracted from e-waste saves a tremendous amount of energy that would otherwise be required to extract and manufacture virgin materials. Energy savings from recycled materials can reach up to 95\% [7]. To give a sense of scale, the production of a computer and a monitor consumes 1.5 tons of water and $240 \mathrm{~kg}$ of fossil fuel in addition to the chemicals and materials used, and the energy saved from the recycling of 1 million laptops can power 3657 homes a year [8]. Such energy savings are translated into economic benefits to the producers as well as pollution reduction to the environment. The economic importance of e-waste does not only lie in the money saved from the urban mining of materials, yet the handling and recycling of e-waste create job opportunities which benefit the local communities. It has been estimated by Electronics Takeback Coalition that for every 10,000 ton of materials reused in computers, 296 more jobs are created [2].

\section{Current E-Waste Situation in Egypt}

\subsection{Overview}

Egypt, a country of around 94 million people [10], represents a significant market for consumer electronics. The market was estimated to reach 4.6 billion USD by 2013. Computers represented around $27 \%$ of the consumer electronics market share in 2008, while mobile handsets and Audio-video devices represented $63 \%$ and $10 \%$ respectively. The market growth rate was expected to be $13 \%$ by 2013 [11]. A study attempted to characterize waste for the greater Cairo area, which includes Cairo, Giza, and Qalubia governorates [12]. The results of the study were summarized in Table 2 which shows an estimate of the volume generated of each material from the collected e-waste and the method of managing them whether through exportation as in the case of Printed Circuit Boards (PCBs) and lithium batteries or by local recycling as in the case of plastics, metals and glass. The table also shows that the largest volume generation is PCBs and Plastics respectively, which would suggest the feasibility of considering these two streams for recycling industries in Egypt.

\subsection{Legislations}

Egypt's current environmental law was first approved in 1994. Although the law 
Table 2. Calculated material quantities generated from e-waste in the Greater Cairo Area and their management practices [12].

\begin{tabular}{|c|c|c|c|c|}
\hline Type of Fraction & $\begin{array}{c}\text { Quantity } \\
\text { Ton/Year (Sample } \\
\text { Size } 30 \%)\end{array}$ & $\begin{array}{l}\text { Corrected } \\
\text { Quantity } \\
\text { Ton/Year }\end{array}$ & Main Dealer & Remarks \\
\hline Plastic Fraction & 39.66 & 132 & Plastic recycling companies. & $\begin{array}{l}\text { This amount is produced from the } \\
\text { WEEE only; a larger amount is resulting } \\
\text { from the municicpal waste. }\end{array}$ \\
\hline PCBs of Different Types & 45.456 & 151.52 & $\begin{array}{l}\text { - Waleed Atito-Manshyt Nasser. } \\
\text { - Adel Malak-Ezbet El Nakhl, Qalubeya } \\
\text { - Ammar, Qalubeya is a main exporter of } \\
\text { the PCBs. }\end{array}$ & $\begin{array}{l}\text { These dealers may sell the PCBs to the } \\
\text { formal sector such as EERC, } \\
\text { Recyclobekia and ITG. }\end{array}$ \\
\hline Ferrous Metal & 36.0 & 120.0 & $\begin{array}{l}\text { - Scrap dealers. } \\
\text { - Foundaries. }\end{array}$ & $\begin{array}{l}\text { Scrap dealers compile large quantities to } \\
\text { supply the foundaries. }\end{array}$ \\
\hline Copper Wires & 10.5 & 35.0 & $\begin{array}{l}\text { - Scrap dealers (They compile large } \\
\text { quantites to supply the foundaries). } \\
\text { - Copper foundaries. }\end{array}$ & \\
\hline CRT Glass & 28.2 & 94.0 & Glass recyclers. & \\
\hline $\begin{array}{c}\text { Batteries of Different } \\
\text { Types }\end{array}$ & 21.0 & 70.00 & $\begin{array}{l}\text { - Lead acid batteries go to the lead } \\
\text { smelters. } \\
\text { - Lithium batteries go to main exporters. }\end{array}$ & \\
\hline $\begin{array}{l}\text { Others (Dumped Waste } \\
\text { Including Hazardous } \\
\text { BRF) }\end{array}$ & 15.24 & 50.8 & Currently dumped in the dumping sites. & $\begin{array}{l}\text { This quantity includes hazardous } \\
\text { materials such as fire retardant; it } \\
\text { should be dumped in a hazardous waste } \\
\text { dumping facility. }\end{array}$ \\
\hline
\end{tabular}

was later amended, it never included a section that exclusively discusses the management of e-waste. However, the law addresses the management of hazardous waste under which e-waste may be classified. It also prohibits the imports of hazardous waste and places restrictions on e-waste imports in compliance with the international conventions, such as Basel convention. However, in the year 2007, there was a ministerial decree that allowed the import of used computers and other electronics under the condition that they are no more than five years old; this resulted in imports of electronics that is about to reach its end of life. The environmental law establishes the Egyptian Environmental Affairs Agency (EEAA) as a regulatory body that sets the environmental action plan and supervises any violations of the environmental law including mismanagement of all waste types [11] [13].

It is important to mention some regulatory procedures addressing the handling of hazardous waste to which e-waste can be linked. First, handlers are required to keep hazardous waste separate from all other wastes generated and collected. Second, they must keep a track record of the quantity and quality of the collected hazardous waste; this requires the categorization of the collected waste. Moreover, the storage and handling locations have to meet safety standards to ensure the safety of both the handlers and the public. Therefore, waste must be stored in solid containers made out of leak-proof materials that are nonporous. Regarding the treatment and utilization of hazardous waste, the law requires that organic and nonorganic substances, as well as ferrous and non- 
ferrous metals, are recovered and reused or recycled. This is subject to their reusability and recyclability [13].

Sustainable Recycling Industries (SRI) recently published a report reviewing the Egyptian laws governing e-waste and comparing them to the European standards [14]. From the report, it can be seen that:

1) The Egyptian law, similar to the EU regulations, requires EIA for any activity carried out, and the establishment is required by law to keep records of its impact on the environment ready at all times to avoid being shut. However, this does not secure enough traceability for all WEEE with volumes and quantities.

2) The Egyptian law requires no training to workers or separate risk assessment for the activities of the establishment

3) Regarding the WEEE handling, the Egyptian law mandates the following of health and safety regulations for the workers as well as providing all required precautions to avoid leakages or emissions. However, the law does not address specific cases of e-waste streams management like in the case of EU regulations. The Egyptian regulations also do not ensure the safety of electronic equipment which could have been reused. This is also apparent in laws governing the transportation of waste, where greater attention is given to the environmentally sound and health and safety than is given to the undamaging handling of equipment.

\subsection{E-Waste Management Practices}

In their comprehensive needs assessment report about the e-waste in Egypt, Centre for Environment for the Arab Region and Europe (CEDARE) reviews the nature of the Egyptian e-waste management process [11]. It states that the e-waste collection system in Egypt is, mainly dominated by street peddlers, locally known as "Robabkia", who buy old household items. In a comparison between the quality of e-waste retrieved by street peddlers and street scavengers, it was found that wastes collected by street scavengers are characterized by being mainly plastic while that collected by street peddlers has more equipment of a better condition [12]. For large quantities of e-waste that are produced from large organizations, they are sold in formal bids held to sell them to big waste dealers. The system is mostly unregulated by the government. After the collection process, e-waste is sorted in formal and informal dumpsites. A portion of the collected e-waste, with no estimated size, is sold to formal and informal workshops, mainly found in densely populated areas. These shops either repair and resell devices or use parts of the devices as spare parts to fix other devices. It is common that recyclers sell independently each material acquired from the dismantling of e-waste [11].

A common practice to extract metals from e-waste wires and integrated boards is open burning. As for small parts like keys that cannot be sold in the markets, they are disposed of in open spaces near the markets. The recycling of WEEE in Egypt is through the selling of collected devices and equipment in five main markets spread around Cairo in the poor and populated areas. These 
markets are Shoubra El-Khema, El-Warrak, El-Kollaly, El-Emam El-Shafie and El-Matareya [11]. There is no real recycling in Egypt for e-waste components except for plastic which is recycled in the collection sites mainly found in Manshiyat Nassir where there are recycling factories there. As for the rest of the components, they are mainly collected and sold to dominating collectors in each area who then collect them and prepare them for exportation [12]. China is a major importer of recovered materials from WEEE as well as certain valuable parts such as the PCBs and processors [15].

According to reports prepared by the Ministry of Environmental Affairs [16], the recycling of WEEE in Egypt is around 1\%. The unregulated management of the system results in processing centers facing problems of unidentified mixed materials as well as sorting problems, especially for batteries. The handling process is also considered to be of extreme danger, as women and children take part in it; smashing the old devices.

As for the remaining fractions that are meant to be landfilled, these fractions usually contain hazardous material, which by law are required to be landfilled in the only hazardous waste dumping facility in Egypt located in Nasiriya at Alexandria governorate. The fraction of hazardous waste from the e-waste dumped is estimated to be $8 \%$. However, the costs of dumping discourage handlers especially since there are still the transportation costs for the waste from any part of Egypt to the dumping facility in Alexandria, a seaport in the north of Egypt. As a result, illegal dumping of hazardous waste in municipal dumping sites is common [12]. Even in the case of non-hazardous fractions, they end up being openly dumped instead of safely landfilled. The remaining fractions are commonly Styrofoam used in the insulation of fridges, rusted iron parts, hard fiberboards mixed with plastics or metals, and the remains from PCBs after the extraction of all precious metals [15].

In their recent study about the informal sector which is handling e-waste in Egypt, [12] highlighted the challenges facing the informal sector. First, there is the absence of legislation which directly addresses e-waste. This results in the nonexistence of a specific entity that is in charge of e-waste handling and monitoring in Egypt as well as the absence of an accreditation system that would guide the proper management of e-waste by the private sector engaged in the process. Among the other challenges mentioned is the absence of take-back schemes and EPR programs which combined with the reluctance of the consumers to give away their used EEE at its EOL for free or at a low-price result in the aggravation of the problems faced by the handling sector. Finally, there are challenges related to the lack of skills and awareness about the threats associated with the improper handling and the inflated prices of machinery needed for sound management and recycling.

\section{Sustainable Guideline for the E-Waste Sector in Egypt}

Based on the findings from the literature review, the Egyptian laws and policies 
indirectly tackle the e-waste problem. In addition, the lack of enforcement and the absence of a specialized entity which handles the entire e-waste management process results in compromising the effectiveness of the current framework upon which the Egyptian e-waste management system is operating.

The proposed guideline is based on the experiences of other developing countries which have been suffering from similar e-waste management problems and have a similar social and economic structure. For instance, Rwanda, India, Uganda and Ghana had their e-waste management dominated by the informal sector. Thus, their recently developed guidelines for e-waste management tackled the inclusion of the informal sector into the new formalized system [17] [18] [19] [20].

Moreover, the policy recommendations fulfill the guiding principles mentioned in the white paper published by StEP initiative [21]. The paper highlighted ten principles for an effective e-waste management system. These principles are concerned with the collection and recycling framework, EPR programs, financing, enforcing and auditing the system, inclusivity of existing informal sector, transparency of the system and creating awareness among all stakeholders and consumers. The guideline also fulfills the sustainability pillars, environmental, social and economic. The recommendations prioritize reuse over the material recovery, and both are prioritized over landfilling and incineration. From the social perspective, the recommendations support job creation and reduce the impact of the formalization on the informal sector as well as helping protect their health and safety through following the correct practices and using protective equipment. Economically, the recommendations establish the recycling industry as a separate sector and encourage investment.

\subsection{Policy Recommendations}

\subsubsection{Define E-Waste Covered by the Policy/Law/Regulation}

The scope of this study is only electronic waste; that is any device that has a printed circuit board with integrated circuits such as computers, laptops, mobile phones, tablets, digital watches, videogames, printers, scanners, etc. Thus, this study does not include electrical household equipment like refrigerators, freezers, vacuum cleaners, toasters, etc. This electrical equipment which is not included in the scope of this study and in the proposed guidelines would remain uncovered by an explicit policy and have to be addressed as well.

The clear definition of the scope of the policy helps define the gaps still existing in the laws to be tackled in the future as well as increases the efficiency of and effectivity of implementing the existing policies through cracking down on loopholes, which can be used to evade the policy.

\subsubsection{Define Aim of the Policy/Law/Regulation}

A clear definition of the objectives of the policy/law/regulation helps assess the gaps and impacts related to the developed policy. The scope of the policy recommendations in this study aims to establish a sustainable e-waste management 
system in Egypt. The system should reduce the environmental impact of e-waste, contribute to decreasing the country's carbon footprint and create green jobs as part of a green circular economy. This would be achieved through the collection and treatment of electronics on the market at their EOL and minimize the overall waste going to landfills.

\subsubsection{Define the Repercussions for Noncompliant Stakeholders}

Having defined and strictly enforced repercussions is vital to the success of any policy. Repercussions can be legal or financial. Legal repercussions can be shutting down noncompliant businesses, taking businesses to court, banning them from operating in certain regions or even at extreme situations jailing of noncompliant business owners. Financial repercussions can be paying fines or higher taxes, reducing tax cuts or abolishing exemptions or paying the cost of the damage done due to noncompliance. A combination of both legal and financial ramifications can prove effective.

In addition to the definition of penalties, defining the enforcing bodies for these penalties and requiring constant reporting in addition to regular auditing is essential to an effective policy.

\subsubsection{Define Responsibilities of All Stakeholders Involved}

A stakeholders' assessment at the beginning of policy/law/regulation formulation is critical in order to define the stakeholders who will be involved in the policy and consider the impacts the policy may have on each of them. This helps anticipate the possible points of argument and resistance from these stakeholders and facilitates tackling these points in advance. In addition, defining the stakeholders allows a clear role distribution of each stakeholder involved hence increasing the effectiveness of the policy/law/regulation. In this study, the stakeholders were defined through a series of interviews following the extensive literature review, and the result of the assessment is illustrated in Figure 1. In the figure, the waste handling side which represents the demand side of the market is divided into the formal and informal sectors. The formal sector stands for e-waste handling businesses that are registered and are formally operating according to the Egyptian law, while the informal sector represents the individual or groups of collectors and scavengers who wander around the Egyptian streets collecting e-waste and operate without license or formal registration, and thus cannot be tracked.

Regarding the key responsibilities of each stakeholder, they are defined below. It is important to note that an entity, individual or a business may perform the role of multiple stakeholders. For instance, a business may be producing computer parts, importing components needed and owns its retail shops which they use as collection points and then performs the roles of collection centers and dismantlers before sending the disassembled products to the recycling facility. Therefore, an entity performing multiple roles can only do so after they acquire all the relevant authorizations and licenses from the responsible government bodies 


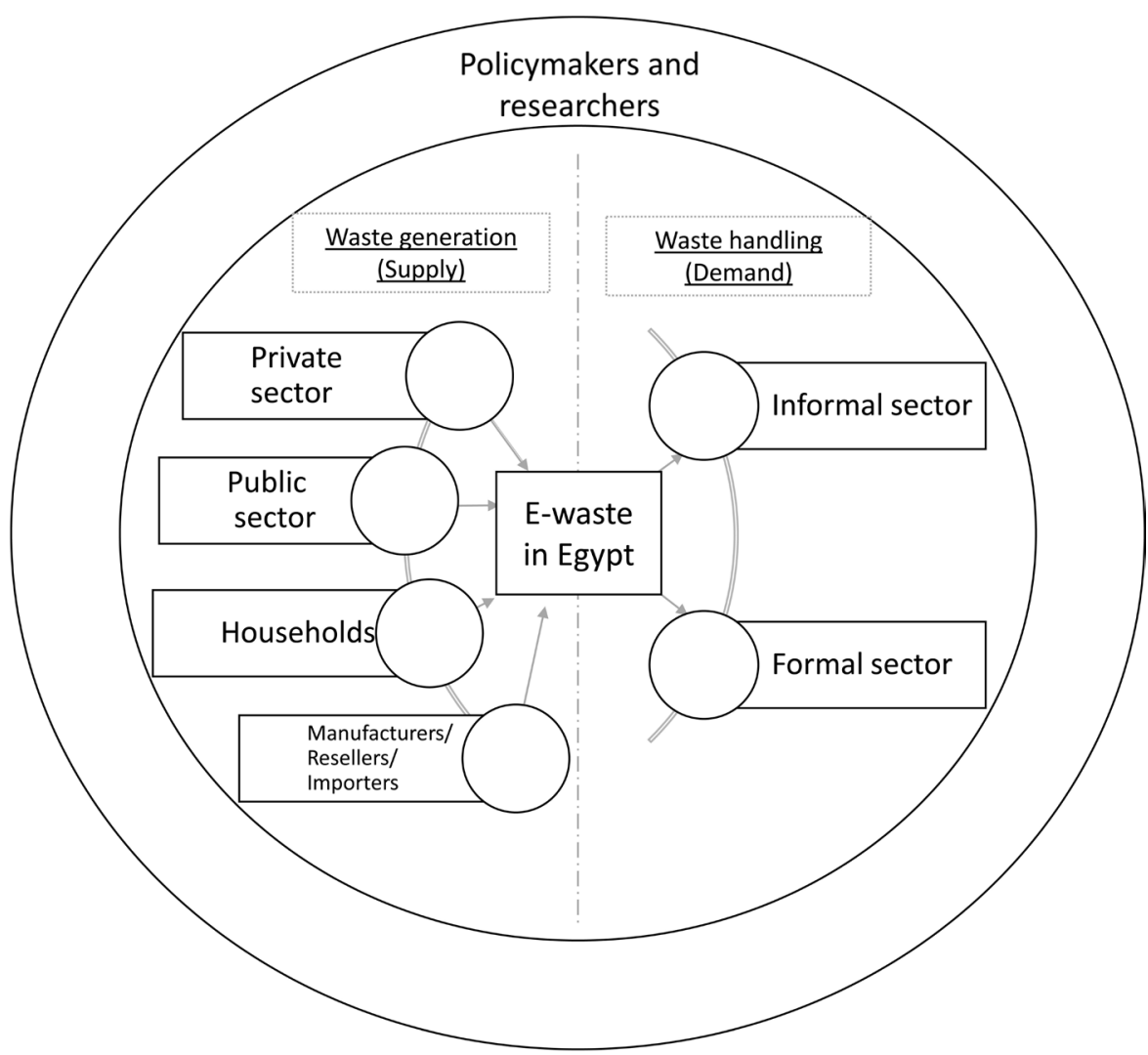

Figure 1. Stakeholders involved in the e-waste sector in Egypt and their interrelations.

to comply with the responsibilities of all the stakeholders whom they are performing their roles.

1) Responsibilities of retailers/manufacturers/importers/dealers

- Implement or participate in an EPR program through a government-authorized PRO organization.

- Collecting their produced or imported e-waste and delivering it to only authorized collection centers, dismantlers or recyclers.

- Creating awareness about the problems associated with untreated and unsafely handled e-waste as well as about the collection and treatment schemes they offer for their products.

- Facilitate the collection and treatment of their products through communication channels such as emails, tollfree numbers and documentation of the collection points available for their products as well as the recycling facilities they will deal with.

- In case of absence of a recycling facility for their products, importers, manufacturers, dealers or retailers are required to establish their own facilities to recycle their products.

- Provide the needed information on the hazardous materials included in their electronics and the proper handling process for the devices and their components at their EOL including instructions for safe dismantling.

- All their electronic products must have visible indelible labeling indicating 
that this has to be safely handled and should not end up in the municipal waste streams.

- Manufacturers should encourage the usage of recycled materials in their products.

- Calculate the estimate needed ARF for their products based on the expected lifespan of their products and get it approved from the PRO.

- Records of e-waste generated from their products must be properly documented and reported to the PRO and the MoEA.

- All their electronics must be registered in a database specifying the details of the product and whether an ARF has been paid for it or not. This database has to be shared with service centers and refurbishers to allow them to provide service to only complying electronics.

- Importers and local manufacturers are required to provide and fund recycling schemes for their older electronics which were put on the market before the introduction of their EPR programs to avoid being fined for improper waste handling of their EOL products.

\section{2) Responsibilities of collection centers}

- All collection centers must keep record of all received, stored, handled and transported e-waste. In addition, records of the entities receiving the collected e-waste, refurbished e-waste and organizations and businesses generating the e-waste must be kept.

- Collection centers must safely store collected e-waste especially the hazardous components like batteries.

- Storage areas must be clearly labelled, well covered and secured.

- Safe transportation of the collected e-waste to only authorized dismantlers or recyclers is a must.

- Clear labelling of all stored or transported components and equipment.

- Collection centers must accept all types of e-waste defined regardless of the brand.

- Using the shared database from retailers, manufacturers, importers and dealers, collection centers would return the refundable part of the ARF if applicable.

- Ensure no damage is caused to the collected e-waste to allow for them to be reused or refurbished.

- Collection centers are to erase the data from all devices permanently to encourage consumers to participate in the collection schemes.

- Data storage devices (hard disks, thumb sticks, etc.) are to be recycled and not refurbished to ensure the data security of their previous owners.

- Collection centers must specify the maximum capacity for their center to allow estimation of the needed dedicated collection centers to accommodate the expected generated quantities.

- Large retailers and retail chains are to be considered as collection centers and must seek the required licenses; they should collect any electronic dropped by the consumer as long as they are defined as e-waste. 
- For collectors from the informal sector, they only need to acquire a collection license and get registered as a certified collector in a PRO to be able to continue to operate. The registration will require them to report the collected and handled amounts as in the case of a collection center.

- Manufacturers, dealers, importers or retailers may contract with registered collectors from the informal sector to provide Door-to-Door collection or other types of collection as a part of their EPR program.

\section{3) Responsibilities of refurbishers and service centers}

- Service centers must not provide any service or maintenance to devices that are not registered in the shared database until they are registration and their ARF is paid by the consumer. For instance, cellular service providers would refuse to operate a phone that is not registered in the database until its owner registers and pays the specified ARF.

- Register non-registered devices before reselling them. Their new owners must pay an ARF.

- Second-hand stores handling electronics are to be considered as refurbishers and service centers and thus, must comply with the regulations put for refurbishers and service centers.

- Follow safety regulations in handling the received devices.

- Erase data permanently from all devices received for their EOL using physical punching of the storage device.

- Keep accurate records of the electronics received, their status and the handling process for each electronic device and component and regularly report to the PRO and the MoEA.

- Storage areas must be clearly labelled, well covered and secured.

- Clearly label all stored or transported electronic components and equipment.

\section{4) Responsibilities of dismantlers}

- Safe handling of all received electronics.

- Perform testing on components and electronics at each phase of dismantling to separate reusable from non-reusable components and parts.

- Separate and safely store and transport handled components to authorized recyclers only.

- Clear labelling of all stored or transported components and electronics.

- Have enough secured and well covered storage area to accommodate storage of electronics and dismantled components a specified amount of time (ex.180 days).

- Specify the dismantling center capacity to allow estimation of the needed centers to accommodate the expected generated quantities.

- Perform pretreatment beyond dismantling only if authorized.

- Comply with environmental and safety regulations including providing PPE to workers, installing air and water pollution control, dust control and noise control systems and ensure proper ventilation of the dismantling facility.

- Keep accurate records and report to the PRO and MoEA the type and quan- 
tity of e-waste received, dismantled, transported, sent for landfilling, exchanged, stored or sent for recycling. In addition to keeping record of the receiving entities of each component transported out of the facility.

- Ensure safe landfilling of nonrecyclables in authorized landfills only.

- Participate in waste exchange programs.

\section{5) Responsibilities of recyclers}

- Comply with environmental and safety regulations including providing PPE to workers, installing air and water pollution control, dust control and noise control systems and ensure proper ventilation of the recycling facility.

- Participate in waste exchange programs for byproducts and materials not handled by the recycling facility.

- Keep accurate records and report to the PRO and MoEA the quantities and types of e-waste received, recycled, and materials recovered from recycling, waste and byproducts produced, stored, exchanged or landfilled.

- Ensure landfilled waste is sent to only authorized landfills.

- Wastes to be landfilled must not have an alternative usage or recycling method and cannot be exchanged in any waste exchange program.

- Report landfilled wastes and byproducts to the PRO and MoEA to help define gaps and find alternatives.

- Clear labelling of all stored or transported materials.

- Have a wastewater treatment facility on-site or contract with an off-site facility which can handle the generated volumes and the responsibility of safe transportation is on both parties.

\section{6) Responsibilities of local government/MoEA/ WMRA}

- Recognize the recycling industry as a separate industry.

- Assist and facilitate the formalization of individual informal handlers and recyclers under a collective facility.

- Provide tax incentives for the industry including tax cuts and subsidies.

- Provide special financing programs for the micro, small and medium recycling businesses.

- Facilitate the obtaining of land needed for dismantling or recycling facilities in industrial areas through leasing and lease-to-buy contracts.

- Include dismantling and recycling techniques and methods into vocational schools to introduce calibers to the industry.

- Spread awareness about e-waste, its safe handling practices and safety hazards associated with improper handling through awareness campaigns and inclusion in educational curricula.

- Audit PROs, importers, dealers, recyclers, dismantlers and landfills.

- Issue authorization for the different entities to operate in the sector only after participating in a PRO.

- Stop operating licenses of all manufacturers, importers, retailers and dealers who do not have an EPR program for their electronics.

- Set recycling and handling targets for both handlers and e-waste generators. 
- Customs must collect and keep record of detailed data about imported electronic products including the constituting materials and quantity of products and ensure they are covered by an EPR scheme before clearing the imported goods.

- Refuse entry to any devices that are not registered by their importers in an authorized recycling scheme.

- Monitor local and international donations of electronic devices to ensure electronics are functional, and that they reach their recipients without ending up as e-waste. In addition, ensure these donated electronic devices are registered for recycling at their EOL to avoid using donations as a method for recycling evasion.

- Issue list of authorized dismantlers, collection centers, PROs, recyclers and landfills as well as waste exchange programs and their participants to ensure transparency and ease of access to information.

- Ensure there are enough facilities to recycle the generate waste and encourage the establishment of new facilities that handle different materials and products.

- Establish Egypt as a regional recycling facility to ensure economies of scale for the establishment of state-of-the-art recycling facilities.

7) Responsibilities of Producer Responsibility Organizations (PROs)

- Handle the collected funds from importers, manufacturers, dealers, retailer as well as the ARF collected from consumers.

- Organize and handle the financing of the recycling expenses for participating entities such as dismantlers, recyclers or collection centers.

- Provide trainings for the workers in the recycling sector.

- Audit facilities to ensure applying the law and the good usage of provided recycling funds.

- Collect recorded data from producers, importers, dismantlers, recyclers, landfills and all participants in waste exchange programs.

- Audit facilities to ensure health and safety of the workers, availability of PPE and the environmentally sound operations.

- Handle the waste exchange programs, promote them and partner with other industries to form a wide network of participants benefiting from the program.

- Ensure all participating producers, importers and dealers have EPR programs for all their products and report noncomplying parties to the ministry for fines and legal persecution.

- Monitor the overall e-waste management process from the collection to recycling and landfilling to ensure the sound management of products.

- Provide and handle collective EPR programs for producers, importers, dealers or retailers willing to transfer their extended responsibility to a specialized entity in return for a premium fee separate from the ARF.

- Provide the needed information for recyclers and handlers about BAT in the 
recycling industry.

- Fund and sponsor research for improving the recycling processes and its sustainability

- Audit and approve the ARF proposed by the producer, importer, dealer or retailer to ensure it covers the recycling cost.

\section{8) Responsibilities of consumers}

- Consumers include organizations, businesses, individuals and entities that purchase, or own electronic devices defined earlier.

- Consumers must dispose of their electronics at their EOL to only authorized collection centers, refurbishers or recyclers.

- If consumers purchased electronic devices abroad and were not registered in the Egyptian recycling database, the consumer must register their electronic device and pay the estimated ARF in order to be able to receive maintenance or service from service centers for their device and cover the cost of recycling at EOL.

\subsubsection{Define Framework for EPR Programs}

- EPR programs can be implemented by individual producer, importer, dealer or retailer for their products or otherwise be collective between multiple producers, importers, dealer or retailers. In case of collective schemes, all participants are held responsible for the implementation of the scheme and the safe handling of the electronic devices.

- The EPR program may be based on an ARF or a pay-on-disposal fee. An ARF must at least be partially refundable to the consumer in order to distribute the cost of recycling between the producer and the consumer with much of the cost on the producer. EPR programs may have the fees paid by the consumers fully refundable conditional to the producer covering for the entire recycling cost.

- Consumers purchasing new electronics and returning their older electronics to the same retailer are to be exempted from the new ARF and may be offered credit from the retailer, producer, importer or dealer as part of the EPR program.

- An EPR program must include a waste exchange program for the recycled materials and byproducts.

- EPR programs must be structured in a way to facilitate and ensure the accurate recordkeeping of the generated quantities of e-waste collected.

- An EPR program must be registered under an authorized PRO or a new PRO can be established, and relevant authorizations and licenses are to be obtained.

- The EPR program must be approved by the PRO. This includes reviewing and approving the price estimates for the recycling and handling of product ensuring the cover the operational costs of the collection centers, dismantlers and recyclers. The decision is taken based on consultation with experts and professionals in the recycling industry to ensure sufficient funds are col- 
lected.

\subsubsection{Define Framework for PRO}

- PROs would have a Quasi-governmental status to ensure neutrality and effectiveness.

- A PRO must have on its steering board representatives of all stakeholders included in the e-waste management cycle on their steering committee including a governmental representative.

- The establishment of PROs can be product-based with each electronic product category having its PRO or based on groups of producers, importers, dealers and retailer having various electronic products.

- Operation costs of the PRO are funded by the participating producers, importers, dealers and retailers.

- Any profit generated by the PRO as part of the EPR programs handled must be ploughed back into financing the PRO operations and the EPR programs.

\subsubsection{Develop Partnerships and Establish Egypt as Regional Treatment Center}

Partnerships between different industries and businesses would foster the waste exchange program and widen the network among which produced byproducts and nonrecyclables from e-waste recycling can be traded. This would in turn contribute to the green circular economy and increase the efficiency of material utilization. In addition to partnerships among industries, partnering with international pioneers in the e-waste recycling sector to exchange knowledge on the BAT as well as to boost foreign investments in the sector would help develop the e-waste recycling sector in Egypt.

Since e-waste handling and management is still in its enfant stage, not only in Egypt but in the entire Middle East and Africa region, establishing the sector in Egypt and positioning Egypt as region treatment center which handles and recycles the e-waste generated in the region would create economies of scale for the existing investments in the sector and encourage the establishment of new state-of-the-art facilities to take advantage of the huge economic potential in the underdeveloped sector.

\subsubsection{Define and Facilitate Alternatives for Items and Materials that Cannot Be Recovered, Reused or Recycled Locally}

Defining a problem is the first step to addressing it. Hence, it is essential to define the e-waste streams and materials which cannot be handled in Egypt at the moment; whether due to the absence of facilities treating these materials and components or because of the lack commercialized treatment technologies which can be used to safely handle these streams and materials. As a result, it is important to introduce the e-waste policies in phases and update them regularly based on the new state of the industry in Egypt as well as the availability of new technologies tackling challenging materials and streams. For instance, currently Egypt has no facility which can treat LCDs, thus it would be a lost opportunity 
not to export this stream until the assessing the feasibility of a treatment of facility of LCDs in Egypt and establishing it. These unrecyclable streams and materials must be defined, and policies need to embrace alternative solutions, in line with international conventions, to the local treatment of these materials.

\subsubsection{Orphaned and Imported Devices by the Customer}

Orphaned electronics are those whose producing companies, importers or dealers are no longer in business and thus cannot be held responsible for their products already on the market. These types of electronics, as well as those which were bought from abroad by individual citizens, pose a challenge to the e-waste handling sector. Since these electronics are not registered in databases and no ARF or disposal fee was paid to cover for their safe disposal. It is essential to integrate these types of electronics in any e-waste management policy. The cost of collection and treatment of orphaned and imported electronics should be distributed among the existing EPR programs according to the market share of each producer, importer or dealer. Incentives to producers, importers and dealers to handle and fund these types of electronics can also be an effective way to encourage the safe handling of these electronics.

\subsubsection{Define Interrelations between Each Stakeholder in the E-Waste Management System}

The complexity of the e-waste ecosystem in Egypt and the interwind relations among the stakeholders can result in some responsibilities being shared among various stakeholders. It is important to define these relations and to hold all parties involved accountable. For instance, some stakeholders may prefer to have a third-party handle their EPR programs. However, it is the stakeholder's responsibility to ensure and audit the compliance of the entity working on their behalf as both would be held responsible for noncompliance.

\subsubsection{Establish a Grading System to Encourage Proper Handling and Compliance}

Grading systems are an effective alternative to financial incentives. They can be used to as a PR method by businesses or to promote dealing with entities with higher rankings. A grading system for e-waste management can be used to grade handling and treatment facilities, producers and importers as well as businesses and organizations which safely handle their generated e-waste. The grading criteria for the system can be based on the following:

- Accurate recordkeeping and reporting.

- Compliance with environmental laws.

- Compliance with international standards and acquiring international certifications.

- Proper handling of e-waste.

- For businesses and organizations generating e-waste, the rating of the handling facilities and partners they deal with.

- The system can be connected to the amount of tax cuts the organization or 
business receives.

\subsection{Technical Guidelines}

Policies pave the road to establishing a system. However, proper understanding of the best practices to apply these policies practically is crucial. Based on the roles defined in the proposed policy guidelines, a sustainable e-waste management system was developed for Egypt. The system is based on the 7R concept, Regulation, Reduce, Reuse, Recycle, Recover, Rethink and Renovate [22]. The system starts with proper collection according to the previously mentioned responsibilities of collectors and is then followed by testing. The significance of testing as part of a sustainable system is that it promotes reusability of working devices and components instead of being lost in the recycling process. Products and devices which cannot be reused or refurbished would then be sent for disassembly as a pre-processing before upgrading. During the disassembly phase, testing of the disassembled components is also performed to allow the reusability of functioning components. Reusable components can be, for example, Intergraded Circuits, capacitors and resistances and other electronic components mounted on the PCB or screens and displays. In addition, the disassembly phase would also decontaminate the collected e-waste by removing and separating hazardous components. The upgrading phase promotes for recycling and material recovery and it includes the mechanical processing and hydrometallurgy to produce streams of similar materials such as metals and non-metals or ferrous metal, non-ferrous metals and non-metals which can then be reintroduced as raw materials for new products. A visual representation of the proposed system is shown in Figure 2. The figure does not include the landfilling and energy recovery of rejected materials which are still unrecyclable as the phase is discouraged and argued against its sustainability. The different phases are further discussed

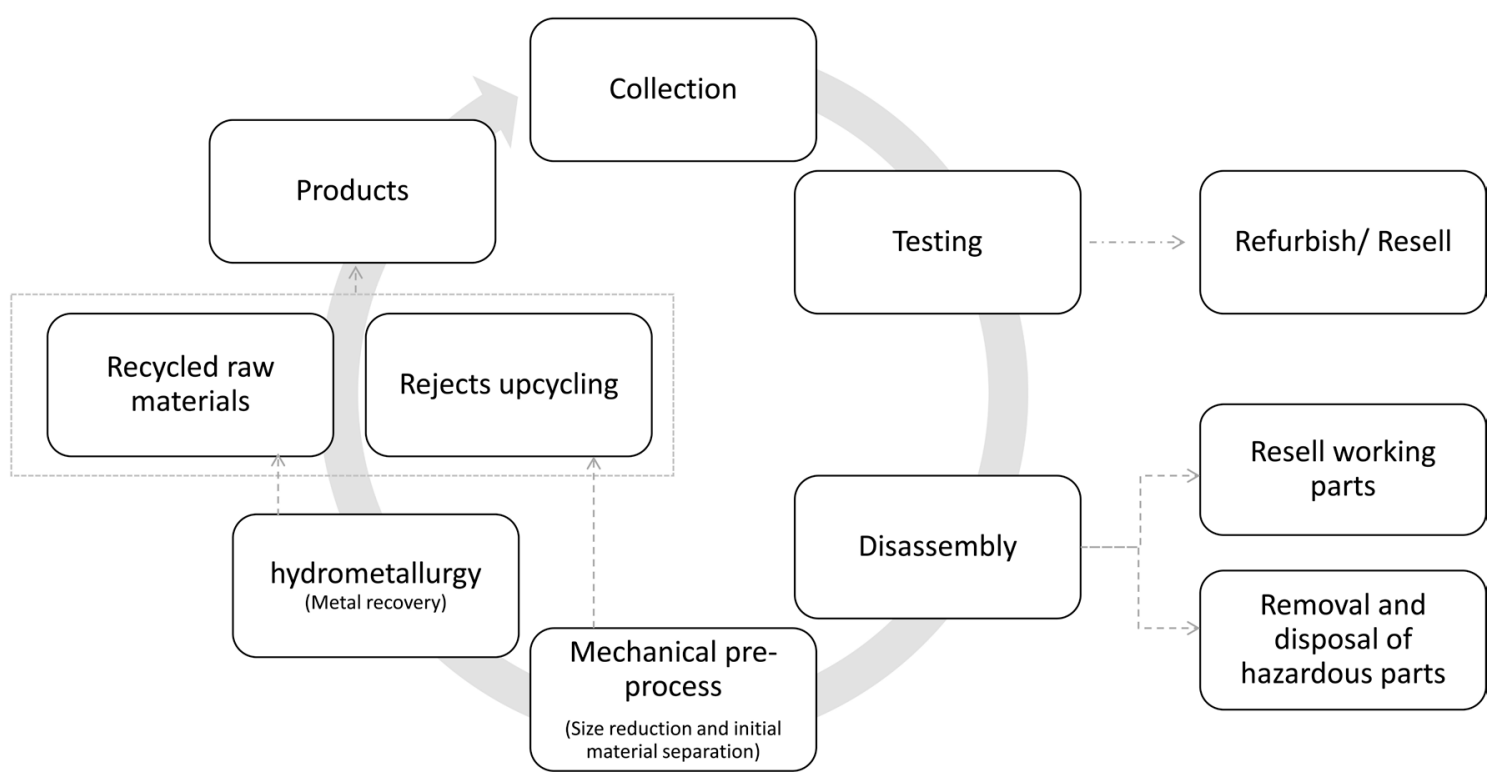

Figure 2. Proposed sustainable handling process of e-waste in Egypt. 
below in details.

\subsubsection{Collection}

Authorized collection centers and collectors are to collect products from end-users and based on the EPR program return the part of the ARF if applicable to the user. For informal collectors, after registering for authorization, they should deliver their collected products to an authorized collection center or to their own authorized collection centers, if applicable, to erase all data on the devices by physically punching the storage devices.

\subsubsection{Testing}

The collection center would then test all collected products to sort them into two streams, functioning or reusable and non-reusable products. The reusable products are sent for refurbishing centers to be maintained and repaired before being resold. Non-reusable products are safely stored and transported to dismantling facilities or dismantled by the collection center, if authorized.

\subsubsection{Disassembly}

The disassembly center would disassemble parts and separate them into various streams. Initially separation would be into hazardous and nonhazardous components. Examples of hazardous components are components containing flame retardants such as some capacitors and plastics. In addition, batteries and accumulators are to be removed from the products and safely stored to avoid leakage or explosion until being transported to the recycling facility. In the case of printers, toners and cartridges should be removed and separated. Nonhazardous components are such as glass, clean plastics and ceramics which were not contaminated by any hazardous chemicals.

The second separation phase would be into components of similar material composition. For instance, all PCBs are to be removed from the products and collected together. Any components mounted on the PCB should be de-soldered and removed leaving the $\mathrm{PCB}$ as a flat metal coated board ready for crushing at the recycling facility. All electric wiring and cables are to be removed, striped and collected together to be sent to copper smelters.

The disassembled components are then tested for the reusability. Functioning or reusable components are resold, while non-reusable components are safely stored and transported to recycling facilities for further processing and treatment.

\subsubsection{Mechanical Processing}

This phase can be divided into two consecutive sub-phases. The aim of mechanical processing phase is to prepare the materials for extraction and refinement to allow for their reintroduction into industries as raw materials.

The first sub-phase of mechanical processing aims to reduce the size of the disassembled components to facilitate their further treatment or transportation to a recycling or material recovery facility. Size reduction can be carried out using hammering, crushing or shredding depending on the component and the 
targeted particle size [23]. For the proposed system in Egypt, hammering or shredding are to be performed first then a grinding step would follow. Precaution should be taken when grinding to avoid the agglomeration of particles which negatively affects the efficiency of the system. It is important to reduce the size components consisting of similar materials together to ease the material separation in the next phase [8] [24]. For instance, components can be initially separated into plastics, metals, ceramics and fiberglass. Afterwards, each stream can undergo size reduction separately. If further classification of the streams can be achieved before size reduction, then this classification is recommended as it will improve the efficiency of material separation in the following sub-phase. Further classification can be for plastics into flame retardant containing plastics and normal plastics or for metals into copper, aluminum and iron. It is important to note that the initial separation into material streams would not produce pure materials but is merely a pre-process for the following phases.

The second sub-phase is the separation of component materials. In this sub-phase, various methods can be used to achieve material separation. Based on the literature, an optimized mechanical separation process was developed [8] [23] [25]-[34]. Each of the initially produced material stream, which was reduced in size, would enter the mechanical separation processes in this sub-phase separately.

The process starts with a two-stage magnetic separation phase, low field followed by high field, to separate the ferrous metals from the nonferrous and nonmetals. The produced material streams would be an iron-nickel based mixture with impurities of other ferrous metals and a nonmetal-nonferrous metals mixture. The nonferrous metals mixture would contain mainly copper, aluminum and precious metals like gold. As for the nonmetal mixture, it would contain mainly plastics or fiberglass depending on the original stream entering the magnetic separation phase. Both produced streams from the magnetic separation phase may include cross-stream impurities. The ferrous mixture would then be sold to steel industries as raw materials for further refinement.

As for the nonmetal-nonferrous mixture, it would be introduced to a gravity separation phase using waterflow tables which efficiently separates nonmetals from metals. Waterflow tables eliminate the need for air filtering systems during the process however, the produced water from separation has to be treated and reused in the process to reduce the environmental impact of the system. The produced material streams from the gravity separation phase would be nonferrous metals and nonmetals streams. The non-metals stream produced from the gravity separation would then be taken for recycling depending on the materials contained. For fiber glass and resins constituting a PCB, these are considered rejects and would go directly to the upcycling phase. As for plastics, depending on their initial separation, clean plastics would be recycled and flame retardant containing plastics would undergo energy recovery as they are hazardous.

Regarding the metals stream produced from gravity separation, they would 
then be introduced to an electrostatic separation phase using eddy currents. The phase produces aluminum, inorganic impurities and copper mixture containing precious metals. An additional electrostatic separation phase using triboelectric or high-speed and voltage corona separation can be added for improved purity of the produced streams. The choice between triboelectric or corona is decided based on the entering stream and the required material to be extracted. Triboelectric is preferred for metal streams and corona is proffered for nonmetal streams. The aluminum produced from the electrostatic separation would be sold to aluminum industries as raw materials while the inorganic impurities would be upcycled using the same method used for the fiberglass and ceramics. The remaining copper-precious metals mixture would then undergo refinement using hydrometallurgical techniques.

\subsubsection{Hydrometallurgical Metal Recovery}

Hydrometallurgy is chosen over pyrometallurgy as it is less costly and requires no special equipment making it more suitable for small and medium businesses handling intermitted supplies of e-waste [8] [27] [35]; . The copper and precious metals extracted from the mechanical processing phase would be separated and purified into their respective raw materials using cyanidation process [36]. However, it must be obligatory for all recyclers performing hydrometallurgy to have a cyanide treatment phase using SART [37]. This would make the phase more environmentally friendly and cost efficient, thus ensuring the sustainability of the e-waste management system.

\subsubsection{Rejects Recycling and Upcycling}

The entire e-waste system produces byproducts, wastes and rejected materials at each phase. In order to mitigate the effect of these produced wastes, it is important to implement the waste exchange program across industries. For instance, the SART method produces gypsum which can be used by cement industries. The contaminated plastics and thermoplastics can be used as fillers by chemical industries such as paint and concrete while the clean plastics and thermosets can be pelletized and used in plastic industries.

The fiberglass from PCBs after extracting the metals can be upcycled into tabletops or tiles which can be used as an alternative to marble. The grinded fiberglass when mixed with $20 \%$ polystyrene and molded under pressure and temperature, can produce a material of higher abrasion resistance and bending strength compared to marble [38].

A summary of the material flow during the different phases of e-waste management and material recovery is shown in Figure 3.

\subsubsection{Prioritization of Materials to be Handled}

Given the wide variety of materials which are included in e-waste, which vary in both their economic value and toxicity level, it is important to prioritize the materials to be handled. Materials included in e-waste can be classified according to toxicity into two categories, high toxicity and medium and low toxicity. As for 
their economic value, they can be categorized into materials of high economic value and materials of low economic value. For better visualization of the different materials and the categories they belong to according to their toxicity and economic value, a four-quadrant matrix can be used, as shown in Figure 4.

Materials having high economic value are usually the materials targeted by the recyclers and pose the least problem to the e-waste management system. On the other hand, materials which have high toxicity, that is they contain substances which pose a threat to the human health or the environment, and low economic value such as plastics containing BFR and fiber glass from PCBs are the most challenging. Since recyclers are the least interested in these materials and usually

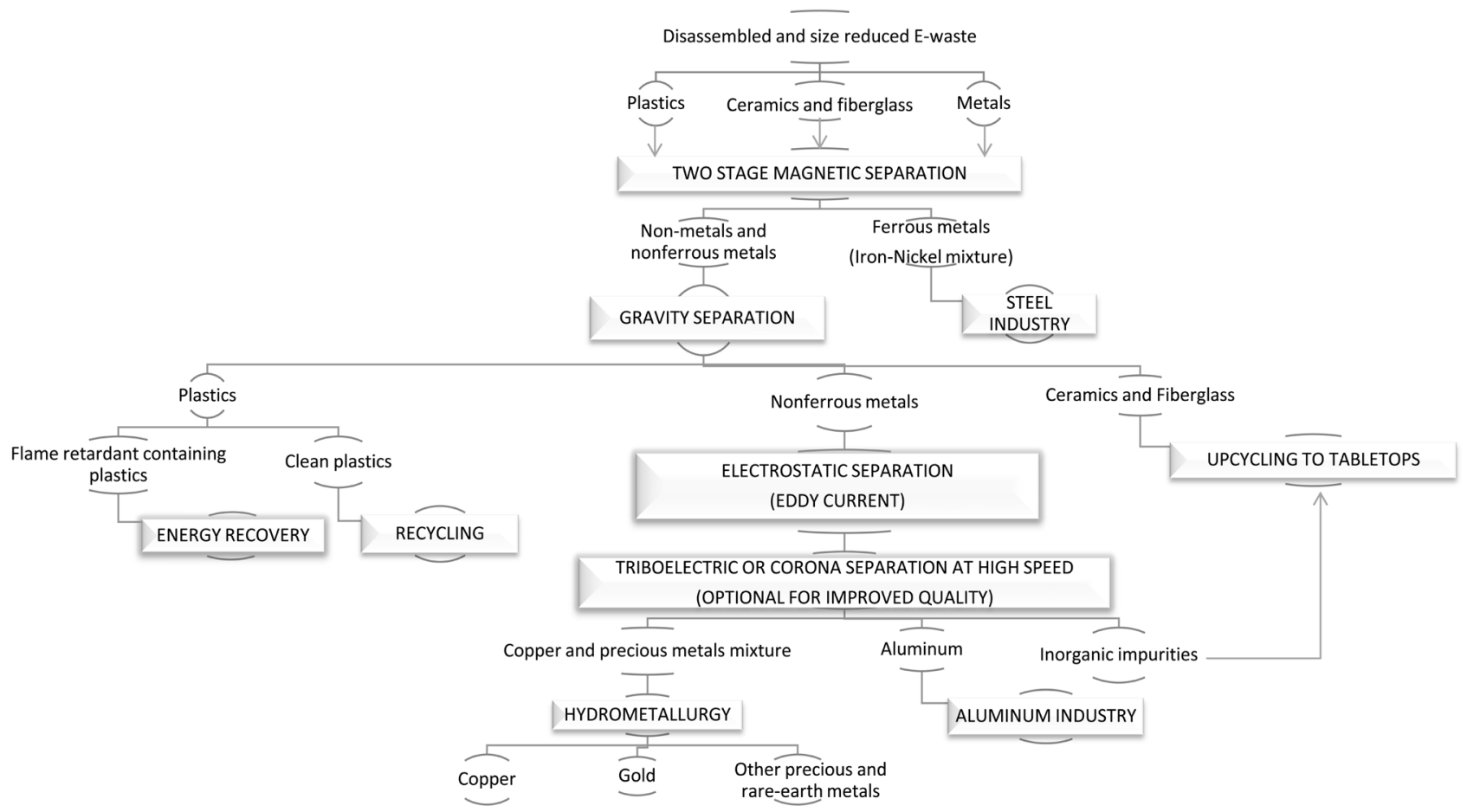

Figure 3. Material flow diagram for the proposed sustainable e-waste processing technique.

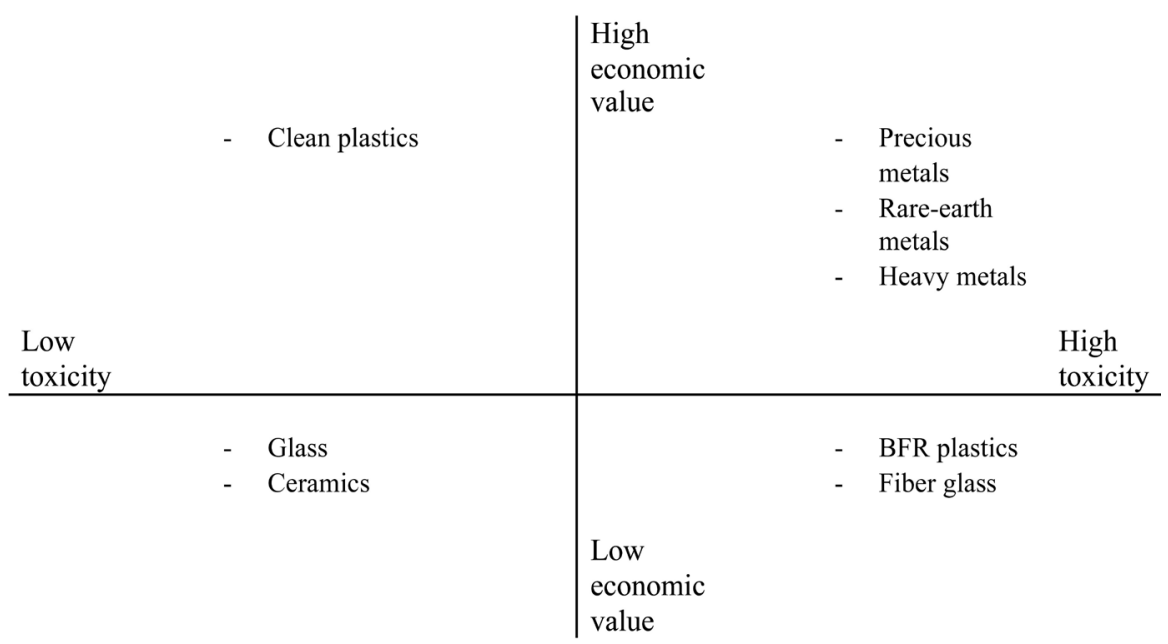

Figure 4. Matrix for economic value and toxicity level of materials in e-waste. 
end up as rejects being landfilled, dumped or disposed of in open streams. These materials should be given the highest priority in handling the materials included in the generated e-waste. As for the remaining materials the priority should be set as:

1) High toxicity- low economic value.

2) Low toxicity- low economic value.

3) High toxicity- high economic value.

4) Low toxicity- high economic value.

The reason behind assigning this priority sequence is because low economic value materials are the least appealing to the recyclers and thus needs to be incentivized by the government to attract recyclers. However, high-value materials would need the least intervention since recyclers are already targeting these materials for their significant profit. Thus, the attractiveness of high-value materials and the profits generated from their handling can be used to self-finance their handling system in addition to provide funds for the materials of lower economic value, hence establishing an overall self-sufficient e-waste handling system which needs limited external financing and intervention.

\section{Conclusions}

This paper attempted to define the current e-waste status in Egypt. It reviewed the available legislations and common handling practices, which both show that e-waste handling in Egypt is still in its natal stage. Given the unregulated nature of the e-waste sector in Egypt, it is heavily dominated by the informal sector that follows primitive practices and manual techniques to handle the collected e-waste. This leads to loss of economic opportunities and wasting resources in addition to posing environmental and health hazards to handlers and workers involved in the sector and residents living near e-waste handling areas. The situation assessment also revealed that there is a lack of a tracking system of the generated amounts of e-waste in Egypt which contributes to uncertainties and inefficiencies in enforcing the current environmental regulations and laws in place. The paper has also attempted to assess the feasibility of establishing an e-waste recycling industry in Egypt. Based on the literature, preliminary estimations of the generated volumes reveal a great potential for businesses starting in the e-waste recycling sector.

Guided by these findings and the publications of other developing African countries in the e-waste management sector, the proposed guideline for sustainable e-waste management in Egypt was developed. The guideline had the Cradle-to-Cradle approach at its core which encourages improved utilization of materials and resources, the establishment of a green circular economy in Egypt and creates green jobs to the local communities. The proposed guideline has also diverted most of the managing, auditing and tracking burden from the government to the PROs to ensure efficiency and decentralization. With the improved auditing and recordkeeping of the generated and managed e-waste in Egypt, 
making informed decisions, updating policies and enforcing laws upon noncompliant parties is facilitated. In addition, the guideline proposes an optimized e-waste management cycle and the use of treatment technologies that fit the Egyptian business ecosystem, integrate and formalize the informal sector into the sector as well as mitigate the environmental impact of the generated e-waste volumes and the byproducts from their treatment.

\section{Conflicts of Interest}

The authors declare no conflicts of interest regarding the publication of this paper.

\section{References}

[1] Tansel, B. (2017) From Electronic Consumer Products to E-Wastes: Global Outlook, Waste Quantities, Recycling Challenges. Environment International, 98, 35-45. https://doi.org/10.1016/j.envint.2016.10.002

[2] Kumar, A., Holuszko, M., Crocce, D. and Espinosa, R. (2017) E-Waste: An Overview on Generation, Collection, Legislation and Recycling Practices. Resources, Conservation and Recycling, 122, 32-42.

https://doi.org/10.1016/j.resconrec.2017.01.018

[3] Perkins, D.N., Brune Drisse, M.-N., Nxele, T. and Sly, P.D. (2014) E-Waste: A Global Hazard. Annals of Global Health, 80, 286-295. https://doi.org/10.1016/j.aogh.2014.10.001

[4] Kiddee, P., Naidu, R. and Wong, M.H. (2013) Electronic Waste Management Approaches: An Overview. Waste Management, 33, 1237-1250. https://doi.org/10.1016/j.wasman.2013.01.006

[5] Reis De Oliveira, C., Bernardes, A.M. and Gerbase, A.E. (2012) Collection and Recycling of Electronic Scrap: A Worldwide Overview and Comparison with the Brazilian Situation. Waste Management, 32, 1592-1610. https://doi.org/10.1016/j.wasman.2012.04.003

[6] Baldé, C.P., Wang, F., Kuehr, R. and Huisman, J. (2015) The Global E-Waste Monitor 2014. Tokyo \& Bonn.

[7] Nnorom, I.C. and Osibanjo, O. (2008) Overview of Electronic Waste (E-Waste) Management Practices and Legislations, and Their Poor Applications in the Developing Countries. Resources, Conservation and Recycling, 52, 843-858. https://doi.org/10.1016/j.resconrec.2008.01.004

[8] Kaya, M. (2016) Recovery of Metals and Nonmetals from Electronic Waste by Physical and Chemical Recycling Processes. Waste Management, 57, 64-90. https://doi.org/10.1016/j.wasman.2016.08.004

[9] Widmer, R., Oswald-Krapf, H., Sinha-Khetriwal, D., Schnellmann, M. and Böni, H. (2005) Global Perspectives on E-Waste. Environmental Impact Assessment Review, 25, 436-458. https://doi.org/10.1016/j.eiar.2005.04.001

[10] CAPMAS (2019) Central Agency for Public Mobilization and Statistics. Egypt in Figures. http://capmas.gov.eg/Pages/Publications.aspx?page_id=5104\&Year=23332

[11] Centre for Environment for the Arab Region and Europe (2011) Needs Assessment of the E-Waste Sector in Egypt.

[12] Soliman, F. and Boushra, M. (2017) Mapping of Informal Sector Involved in E-Waste Collection. SECO. 
[13] Rochat, D. and Grégoire, G. (2014) Preparatory Information for the Implementation of an Electronic Waste Pilot Project in Egypt. The World Bank, Washington DC.

[14] Soliman, F. and Abdelmoniem, G. (2017) Legislations Report: Review of the Existing Egyptian Legislation Applicable to E-Waste Recycling Compared to the European Standards on E-Waste Recycling WEELABEX. SECO.

[15] Degreif, S., Mehlhart, G. and Merz, C. (2014) Global Circular Economy of Strategic Metals: Best of Two Worlds Approach (Bo2W)-Chapter Egypt. OEKO-Institute E.V., Darmstadt.

[16] Ministry of State for Environmental Affairs (2012) Egypt State of the Environment Report 2011.

[17] Central Pollution Control Board (2016) E-Waste Rules 2016.

[18] Environmental Protection Agency (2018) Technical Guidelines on Environmentally Sound E-Waste Management for Collectors, Collection Centers, Transporters, Treatment Facilities and Final Disposal in Ghana.

[19] Kigali (2016) National E-Waste Management Policy for Rwanda.

[20] Government of Uganda (2016) Guidelines for E-Waste Management in Uganda.

[21] Smit, E., et al. (2016) Guiding Principles to Develop E-Waste Management Systems and Legislation.

[22] El-Haggar, S. (2007) Sustainable Industrial Design and Waste Management: Cradle-to-Cradle for Sustainable Development. Elsevier, Amsterdam. https://doi.org/10.1016/B978-012373623-9/50012-5

[23] Işıldar, A., Rene, E.R., Van Hullebusch, E.D. and Lens, P.N.L. (2018) Electronic Waste as a Secondary Source of Critical Metals: Management and Recovery Technologies. Resources, Conservation and Recycling, 135, 296-312. https://doi.org/10.1016/j.resconrec.2017.07.031

[24] Silvas, F.P.C., Jiménez Correa, M.M., Caldas, M.P.K., de Moraes, V.T., Espinosa, D.C.R. and Tenório, J.A.S. (2015) Printed Circuit Board Recycling: Physical Processing and Copper Extraction by Selective Leaching. Waste Management, 46, 503-510. https://doi.org/10.1016/j.wasman.2015.08.030

[25] Xue, M., Li, J. and Xu, Z. (2013) Management Strategies on the Industrialization Road of State-of-the-Art Technologies for E-Waste Recycling: The Case Study of Electrostatic Separation-A Review. Waste Management \& Research, 31, 130-140. https://doi.org/10.1177/0734242X12465464

[26] Mezenin, A.O. (2017) Specifics of Crushed Electronics Scrap Components Electrostatic Separation. Obogashchenie Rud, 49-53. https://doi.org/10.17580/or.2017.06.09

[27] Abdelbasir, S.M., El-Sheltawy, C.T. and Abdo, D.M. (2018) Green Processes for Electronic Waste Recycling: A Review. Journal of Sustainable Metallurgy, 4, 295-311. https://doi.org/10.1007/s40831-018-0175-3

[28] Crawford, C.B. and Quinn, B. (2017) Microplastic Separation Techniques. Elsevier, Amsterdam. https://doi.org/10.1016/B978-0-12-809406-8.00009-8

[29] Rao, S.R. (2006) Physical and Physico-Chemical Processes. In: Waste Management Series, Vol. 7, Elsevier, Amsterdam, 35-69. https://doi.org/10.1016/S0713-2743(06)80088-7

[30] Haldar, S.K. (2013) Environmental System Management of Mineral Resources and Sustainable Development. In: Mineral Exploration: Principles and Applications, Elsevier, Amsterdam, 267-286. https://doi.org/10.1016/B978-0-12-416005-7.00014-3 
[31] Zhang, L. and Xu, Z. (2016) A Review of Current Progress of Recycling Technologies for Metals from Waste Electrical and Electronic Equipment. Journal of Cleaner Production, 127, 19-36. https://doi.org/10.1016/j.jclepro.2016.04.004

[32] Shapiro, M. and Galperin, V. (2005) Air Classification of Solid Particles: A Review. Chemical Engineering and Processing, 44, 279-285.

https://doi.org/10.1016/j.cep.2004.02.022

[33] Hou, S., Wu, J., Qin, Y. and Xu, Z. (2010) Electrostatic Separation for Recycling Waste Printed Circuit Board: A Study on External Factor and a Robust Design for Optimization. Environmental Science \& Technology, 44, 5177-5181. https://doi.org/10.1021/es903936m

[34] Xue, M., Yan, G., Li, J. and Xu, Z. (2012) Electrostatic Separation for Recycling Conductors, Semiconductors, and Nonconductors from Electronic Waste. Environmental Science and Technology, 46, 10556-10563.

https://doi.org/10.1021/es301830v

[35] Birloaga, I., De Michelis, I., Ferella, F., Buzatu, M. and Vegliò, F. (2013) Study on the Influence of Various Factors in the Hydrometallurgical Processing of Waste Printed Circuit Boards for Copper and Gold Recovery. Waste Management, 33, 935-941. https://doi.org/10.1016/j.wasman.2013.01.003

[36] Rao, S.R. (2006) Metal Recycling. In: Waste Management Series, Vol. 7, Elsevier, Amsterdam, 167-268. https://doi.org/10.1016/S0713-2743(06)80092-9

[37] Estay, H. (2018) Designing the SART Process-A Review. Hydrometallurgy, 176, 147-165. https://doi.org/10.1016/j.hydromet.2018.01.011

[38] Tarek, A. (2019) Sustainability of E-Waste Management: Egypt Case Study. The American University in Cairo. 


\section{Abbreviations}

$\begin{array}{ll}\text { ARF } & \text { Advance Return Fee } \\ \text { BAT } & \text { Best Available Technology } \\ \text { BRF } & \text { Brominated Flame Retardants } \\ \text { CEDARE } & \text { Centre For Environment and Development for The Arab Region } \\ & \text { and Europe } \\ \text { CRT } & \text { Cathode Ray Tubes } \\ \text { EEAA } & \text { Egyptian Environmental Affairs Agency } \\ \text { EEE } & \text { Electrical and Electronic Equipment } \\ \text { EIA } & \text { Environmental Impact Assessment } \\ \text { EOL } & \text { End of Life } \\ \text { EPR } & \text { Extended Producer Responsibility } \\ \text { EU } & \text { European Union } \\ \text { LCD } & \text { Liquid Crystal Displays } \\ \text { MoEA } & \text { Ministry of Environmental Affairs } \\ \text { PC } & \text { Personal Computer } \\ \text { PCB } & \text { Printed Circuit Board } \\ \text { PP } & \text { Polypropylene } \\ \text { PPE } & \text { Personal Protective Equipment } \\ \text { PRO } & \text { Producer Responsibility Organization } \\ \text { SART } & \text { Sulfidization, Acidification, Recycling of Copper and Thickening } \\ \text { SRI } & \text { of Precipitants } \\ \text { StEP } & \text { Solving the E-Waste Problem Initiative } \\ \text { USD } & \text { United States Dollar } \\ \text { WEEE } & \text { Waste Electrical and Electronic Equipment } \\ \text { WMRA } & \text { Waste Management Regulatory Agency } \\ & \end{array}$

